\title{
Corporate Social Responsibility of Mining Companies in Ghana: The case of Newmont Ghana Gold Limited at Ahafo
}

\author{
Daniel Owusu-Ansah ${ }^{1}$, Samuel Adu-Gyamfi ${ }^{1}$, Edward Brenya ${ }^{1}$, Yaw Amo Sarpong ${ }^{1}$, David Damtar ${ }^{2}$ \\ ${ }^{1}$ Kwame Nkrumah University of Science and Technology (KNUST), Ghana \\ ${ }^{2}$ National Research University Higher School of Economics, St. Petersburg, Russian Federation \\ mcgyamfi@yahoo.com
}

\begin{abstract}
It is perceived by many that communities in Ghana that host large scale mining activities are affluent and outpace several other communities in terms of socio-economic development. This seems not to be the case. This notwithstanding, mining companies have an obligation to fulfil towards the communities they operate within as part of their Corporate Social Responsibility (CSR). This necessitated an assessment of the Corporate Social Responsibility of Newmont Ghana Gold Limited at Ahafo in Ghana. This paper considered relevant literature pertaining to the subject matter, the views of community members within the mining enclave of Ahafo as well as that of Newmont Ghana Gold Limited. A sample of 180 respondents was chosen through a purposive sampling technique. Key personalities including an Assemblyman, a Youth Leader, and three resettled persons were interviewed. There was also a focused group discussion among community members. The study found out Newmont has not deviated from its CSR in the region.
\end{abstract}

Keywords: Corporate Social Responsibility (CSR), Newmont Ghana Gold Limited (NGGL), Ahafo Social Responsibility Agreement (ASRA), Ahafo Social Responsibility Forum (ASRF)

\section{Introduction}

Organizations are being called upon to take responsibility for ways their operations impact societies and the natural environment (D'Amato, Sybil and Sue, 2009). This led them to adopt policies and programmes that would enable them establish a balance between meeting the needs of affected societies as well as their basic intent of profit making. These efforts drive at home the concept of Corporate Social Responsibility. This concept since its first usage has been looked at from different perspectives by states, corporations, companies and individuals. It is significant to note that in the Ghanaian society, the mining industry has been one of the leading areas. CSR is mentioned because of the environmental and human rights concerns. This coupled with calls for ethical, social and environmental responsibility from companies operating in rural areas to be ensured (Dartey-Baah and Amponsah-Tawiah, 2012) has generated further interest. However, the role mining companies' play in the area of development in Ghana has been emphasized by Ababio and Boon (2009) when they noted that such pressures are intended to make the mining companies adopt effective Corporate Social Responsibility (CSR) policies and commit more resources to the development of communities in which they operate. This is also to ensure the sustainable development of the country as a whole. Irrespective of the various research on mining and CSR on Ghana; such as Yankson's (2010) work on Wassa West District of Ghana, Opoku et al. (2014) on Tarkwa and Seth Opoku, Amoako-Arhen and Okyere's (2014) glimpse at Tarkwa Nsuaem municipality as well as Adu-Gyamfi et al. (2015) work on Artisanal Mining and its Ramifications on the People of Prestea, little or scant research has been done on the assessment of the CSR of a rising mining giant, Newmont Ghana Gold Limited whose operation is in Ahafo catchment area of Ghana. Comparatively, contrary to other mining towns such as Perth in Australia, Johannesburg in South Africa, Noranda City in Ontario, Canada and Reno in the USA, typical mining towns in Ghana are far from affluent as stated by Opoku et al. (2014) in a research survey of the Tarkwa Nsuaem Municipality of Ghana. It should be useful to find out whether there are negative impacts of Newmont's mining operations on the communities in Ahafo. There is also the need to do an assessment on how Newmont Ghana Gold Ltd has contributed to the socio-economic development of the Ahafo mining communities.

The mining industry and Corporate Social Responsibility in Ghana: According to Ababio and Boon (2009), the concept of Corporate Social Responsibility can be traced back to the middle 1950s when Bowen 
(1953) formally used Corporate Social Responsibility to refer to 'the obligations of businessmen to pursue those policies to make those decisions, or to follow those lines of action which are desirable in terms of the objectives and values of our society.' This traditional notion had gone through various forms but the fact still remains that companies and individuals put up efforts to achieve their business objective of profit making without neglecting the people who are affected by the company's operation. Again, Amponsah-Tewiah and Dartey-Baah (2012) acknowledge the tremendous contribution of mining companies through the provision of support for the protection of the cultural heritage of the country and enhancing community development through the provision of education, employment and other livelihood programs. They pointed out that the operations of some mining companies have also had negative impacts including erosion of cultural values and deprivation of others of their traditional livelihoods through the pollution of water bodies and the environment as well as the purchase of their farmlands (Dartey-Baah and Amponsah-Tewiah, 2012). Arko (2013) also, not differing much from this view pointed out that though the mining companies would like to believe otherwise, there is a widely held perception that their mining activities have been the cause of poverty and a lack of sustainable development in mining communities. The counter argument is that in a developing country like Ghana, poverty is generally pervasive in many communities including that do not engage in mining. Hence Boon and Ababio (2009) postulate that the operations of mining companies do not cause poverty and vulnerability.

To this end, there have been divergent views whether these mining companies do fulfil their CSR or not. This is seen in two perspectives: from the angle of the mining companies and that of members of the communities. Also concerning the members within the community, the views do vary depending on a lot of factors discussed in this paper. Before the discourse sets in, it is essential to point out that the community development approach of investing one US dollar (US\$1) for every ounce of gold produced payable quarterly; and one per centum (1\%) of profit from the gold produced every year (Ahafo Social Responsibility Agreement, 2008; Kapstein and Kim, 2011; Mireku Gyimah, n.d) has been the significant model Newmont operates on with respect to its CSR agenda. This approach seems to be a means towards the fulfilment of mining CSR in Ghana as Atuguba and Dowuona-Hammond (2006) established that in the absence of a clear CSR policy, individuals, advocacy groups and public agencies seeking to hold corporations responsible to their social responsibilities usually encounter difficulties in doing so because of the absence of a readily available source document on CSR for reference. That notwithstanding, mining companies put up measures that would enable them achieve this goal with the employment of not only state laws and principles but also, in consultation with the parties affected or the mining communities to put up some regulations that are agreeable by both parties. This is what Mireku-Gyimah (n.d) explained under his partnership model that in such instance the parties come together to discuss issues of mutual interest, deliberate on their concerns and arrive at decisions that address their concerns and bring mutual benefits. Whereas Akabzaa (2004) negatively portrayed competition in the mining sector to have been breeding poor enactment of mining codes, Barfi and Asare (2008) make mention of the Minerals and Mining Act of 2006 (Act 703) which addresses various pitfalls within the mining sector with respect to CSR which fall within the interest of the local people including resettlement planning and compensation for use of land. This is purposely to address the challenges that do arise on the part of the mining communities since they are usually affected as Jenkins and Obara (2008) indicated that the Corporate Social Responsibility (CSR) programmes of these mining companies tend to give attention to community initiatives as their impact in economic, social and environmental terms is felt greatest at the local level. That notwithstanding, there has been various questions as to whether these mining companies in Ghana do fulfil their corporate social responsibility. It is in the light of this that such an assessment concerning Newmont's operation in Ahafo would have to be amply looked at.

Overview of Asutifi District, Tano North District and Newmont Ghana Gold Ltd at Ahafo: Asutifi and Tano North at Ahafo served as the focal point for this research and are part of the twenty-two districts of the Brong Ahafo region in the Republic of Ghana. Tano North District lies between longitude $7^{\circ} 00^{\prime} 25^{\prime}$, latitude $1^{\circ}$ $45^{\prime} \mathrm{W}$ and $2^{\circ} 15^{\prime} \mathrm{W}$ with a total land surface area of 876 square kilometres whereas its population as of the year 2010 was 78,415(MOFA, 2015). To the North East, it shares boundary with Offinso and to the South West it shares boundary with Ahafo Ano District in the Asante Region (ibid). The Asutifi District on the other hand lies between latitudes $6^{\circ} 40^{\prime}$ and $7^{\circ} 1^{\prime} \mathrm{N}$ and Longitudes $2^{\circ} 15^{\prime}$ and $2^{\circ} 45^{\prime} \mathrm{W}$ and has a land area of 1500 square kilometres and a population estimated in 2010 to be 110,731 . It shares boundary to the north with Sunyani Municipality, Tano North District to the North East, Dormaa District to the North West, Asunafo 
District to the South West and Ahafo Ano North District (Asante Region) to the South East. Some of the towns in these districts are predominantly rural although urbanism is gradually setting in. Thus, their contribution to the economy of Ghana is basically from agriculture and its related activities. Food crops such as maize, cassava, plantain, yam, oil palm, sugarcane, as well as the major cash crop of the nation, cocoa are largely cultivated in these areas. The greater numbers of the people of the area are the Asante and Brong groups of Akan. Northern settlers and people from other parts of the country have also lived in these areas for a long time. A greater proportion of children at the area up to school going age are enrolled. Newmont Mining Company has been identified as one of the largest gold producers in the world and is headquartered near Denver, Colorado. It traces its foundation back to 1921 while its public trade started by 1925.Its operation in Ghana dates back to the year 2002 when there was a transfer of concessions from the Normandy Mining to Newmont Mining Corporation (Newmont.com, 2015; Arko, 2013).). Newmont's first operational site in Ghana and Africa in general is found at Ahafo. The project at Ahafo was formalized on December 19, 2003 with the signing of a foreign investment agreement between Newmont and the Government of Ghana. Actual mining commenced in January 2006 and the company poured its first gold from the soils of Ahafo on July 18 1 th $^{2} 2006$ while commercial production commenced in August the same year (Kapstein and Kim, 2011). Fig. 1 shows the mining area including the two districts of Asutifi and Tano North.

Figure 1: Ahafo Mines, showing North and South Area.

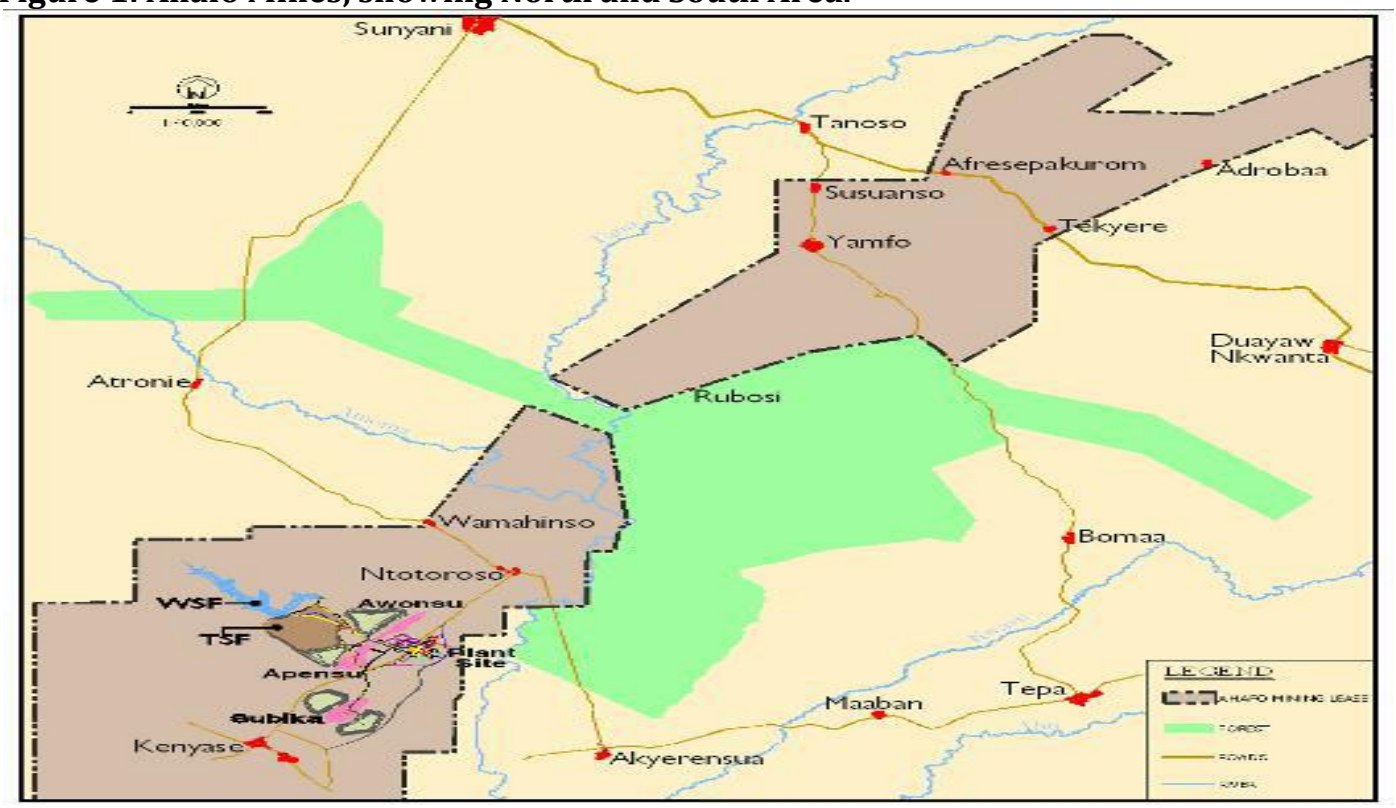

Source: Newmont Ghana RAP, 2009 cited in Asante- Manteaw, 2011

\section{Data collection procedure, sampling and data analysis}

Both primary and secondary sources contributed to the research. Books, journal articles, reports and other research works helped to throw light on the subject matter backed by first-hand information obtained through the administration of questionnaires, interviews, focus group discussions and visitation to specific sites to observe happenings. A sample of 180 people within the study area was chosen to respond to questionnaires. The mining towns were chosen based on purposive sampling with the rationale that they would have the specialist knowledge (SAGE, 2006) about the mine due to their proximity with the mine site. These towns fall within the Asutifi District visa-vis Kenyasi No. 1 and 2, Ntotroso, Gyedu and Wamahinso. Asside they standing the greater possibility when it comes to awareness of the happenings in the mining company, they stand the higher chance of being affected by any negative environmental effects that could come out of the mine. Other towns that formed part of the study included Techire, Afrisipakrom, Yamfo, Adrobaa and Susuanso in the Tano North District. In order to obtain a pluralistic opinion, children (6-14 years), youth (15-39 years) and adults ( 40 year and above) equally represented, each consisting of sixty respondents. The purpose of including children was to ascertain their views on the pros and cons of 
Newmont's operation and impact on their lives and their opinion since they are the future leaders and the bearers of any futuristic repercussions whatsoever of the mining operations. The youth also represented based on such reason and also, help ascertain what Newmont is currently contributing and how it is impacting the lives of the people in the mining area. Adults were not left out in order to establish as how the mining is impacting their lives as parents. An assemblyman, a Youth Leader and three resettled persons were also interviewed. The choice of an assemblyman and a youth leader was not only motivated by their permanent membership on the Ahafo Social Responsibility Forum but also, they serve as opinion leaders and mediate between the mining company and their respective communities. Key areas of focus to assess Newmont's socio-economic role in the region and largely its CSR included human resource development, job creation, health and environment, culture and recreation. Statistical Package for the Social Sciences (SPSS) and Microsoft excel were used to analyze the primary data collected. The views of the respondents were grouped into the key ideas, which constitute the specific research concerns. The statistical tools used included pie charts, frequency tables, bar graphs and percentages. For validity of work, keen attention was given to questionnaires and efforts were made to ensure respondents were free, sincere and opened up to air their views. The analysis was also done by strictly following what was given out by the various respondents so as not to distort the trustworthiness of research outcomes.

\section{Results and Discussion}

The knowledge of the people about the subject was first given a priority in order to obtain undiluted facts for the research. All the respondents affirmed to the fact that they are aware of the operations of the mining company. This confirms not only of effective occupation of the mining company at the region but also, that the people know of what is going on the area whether it is good or bad hence their views do reflect the realities on the grounds as far as Newmont's socio-economic responsibility is concerned.

Figure 2: Awareness of Newmont's operations at Ahafo

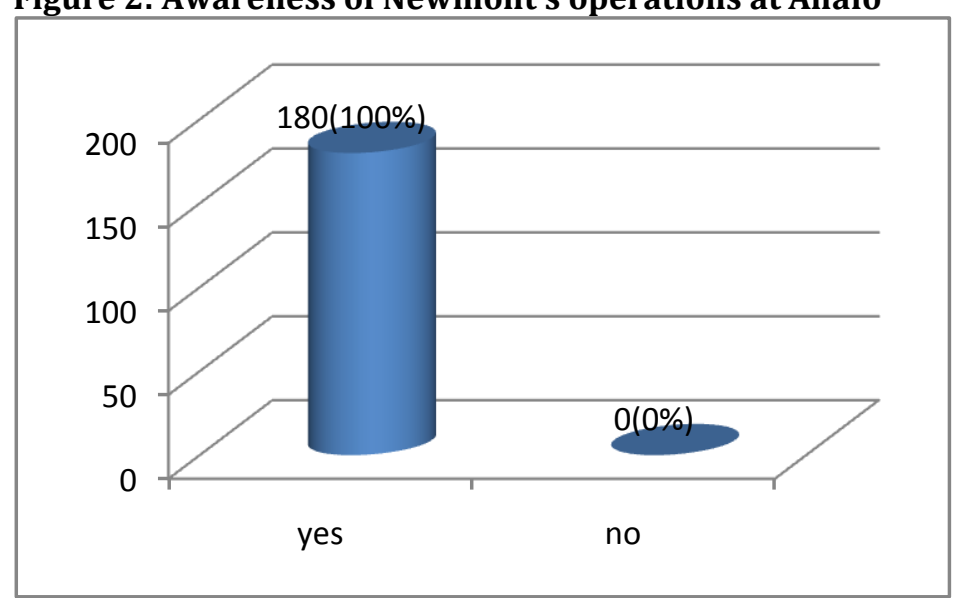

Source: Field Survey, March 2014

Newmont and CSR: Before Newmont started operations at Ahafo, there were various concerns raised by stakeholders and NGOs as well as interest groups such as Wassa Association of Communities Affected by Mining (WACAM) as to whether Newmont would be able to put up stringent measures to protect, sustain and promote the natural cause of events in the region of Ahafo when it proceed to actively mine. Moreover, Ghana has, although sometimes debatable with respect to implementation, a legal framework on mining CSR. Various positions concerning the implementation of mining CSR include seeing it as a philanthropic add on, others see it from a moral perspective while others still attempt to circle it around the hard law against soft law debate whereby Nwete (2007) indicated that the soft law has been of late embraced by many and it saves the problem of companies taking the role of government should hard law be upheld to. Not deviating from this view of operating with soft law had Newmont Ghana Gold Ltd, in consultation with the mining communities and other stakeholders came up with the Ahafo Social Responsibility Agreement. It serves as a code agreeable by all parties to ensure the smooth operation of the mining company as well as the regulation of its operations within the region. This mode of agreement among other things saw the establishment of the 
Newmont Ahafo Development Foundation (NADeF) in 2008 through the Ahafo Social Responsibility Agreement. According to the NADe Froport (2014);

Newmont Ahafo Development Foundation (NADeF) is a sustainable community development foundation established through an agreement between Newmont Ghana Gold Limited and the Ahafo Social Responsibility Forum (represented by 10 Ahafo Mine Communities, Local Government, Regional Government and Civil Society), as a mechanism to share values between the Company and its Stakeholders. NADeF operates in ten Ahafo Mine communities namely; Kenyasi No.1, Keyasi No.2, Ntotroso, Gyedu and Wamahinso in the Asutifi North District and Yamfo, Susuanso, Afrisipakrom, Terchire and Adrobaa in the Tano North District. The Foundation is founded through an annual contribution from Newmont comprising US\$1 per ounce of gold produced and 1\% of net pre-tax profit from the Ahafo Mine with an appropriate contribution of GHC 41 million to date. It is significant to note that Newmont largely contributes towards development of the region through this foundation. That notwithstanding, prior to the establishment of NADeF, Newmont was not keeping blind eye upon development especially in cases where its operations affected the lives of the people. This is because resettlement programmes started before the establishment of this foundation.

\section{Figure 3: An excerpt showing Proportions of expenditure on Development}

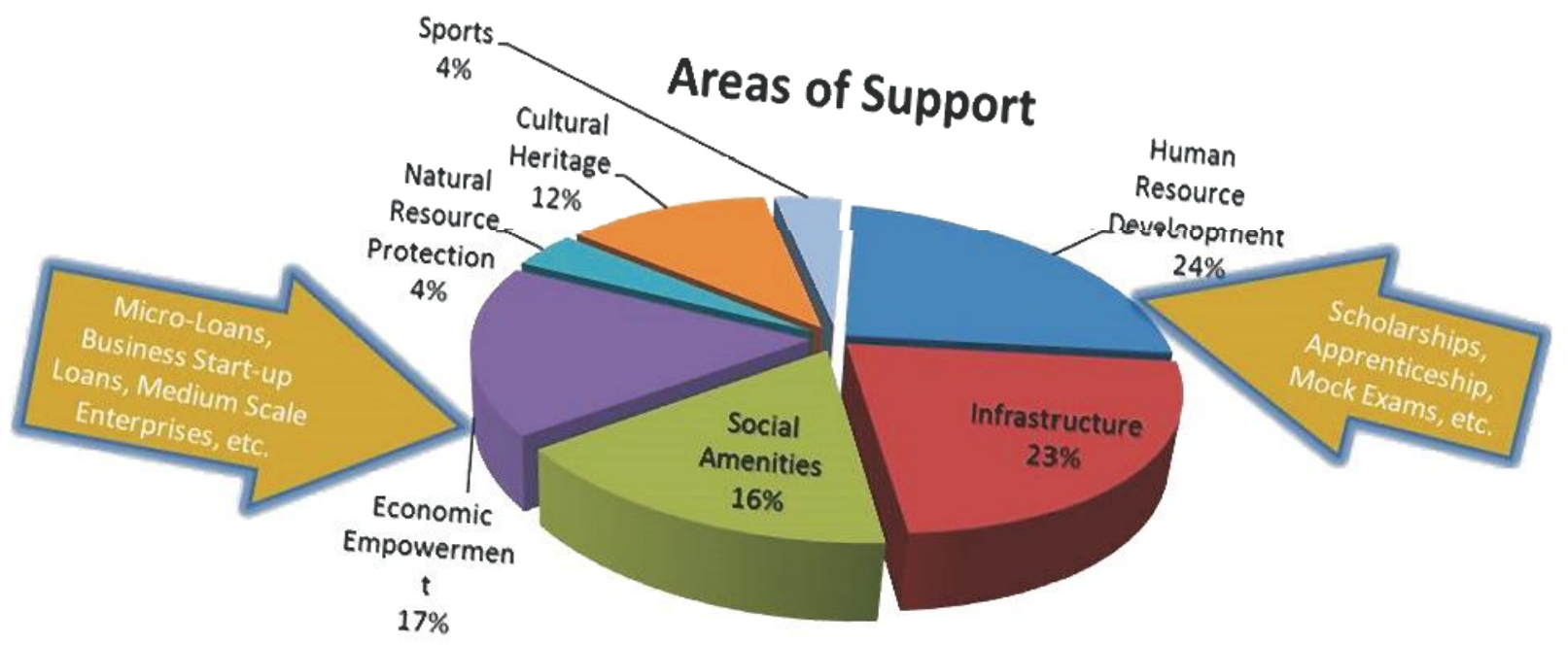

NADeF report, 2014

According to fig. 3, the annual accruals of NADeF concentrate on the various socio-economic aspects of the lives of the people within the mining community. On Human Resources development which encompasses education and job training, twenty four percent of the annual funds are channelled to it, Economic empowerment which looks at building young entrepreneur through microcredit schemes take 17 percent, infrastructure takes 23 percent, social amenities also take 16 percent, 12 percent is channelled to cultural heritage, 4 percent into natural resource protection and the remaining 4 percent into sports. This confirms the observation made on the field that the people have knowledge of Newmont's CSR, a reflection of effective attention to the development of the mining communities of Ahafo. The people within the mining community affirm to the fact that Newmont do have a CSR to fulfil as part of its operations at Ahafo. The Fig. below indicates that 168 of the respondents representing 93.3 percent acknowledge that Newmont have such obligation to fulfil against twelve respondents representing 6.7 percent who did not affirm to that. This is an indicative that the significant number of the people within the Ahafo mining Community looks up to Newmont to do justice to its CSR. 
Figure 4: Newmont Having a CSR to adhere to

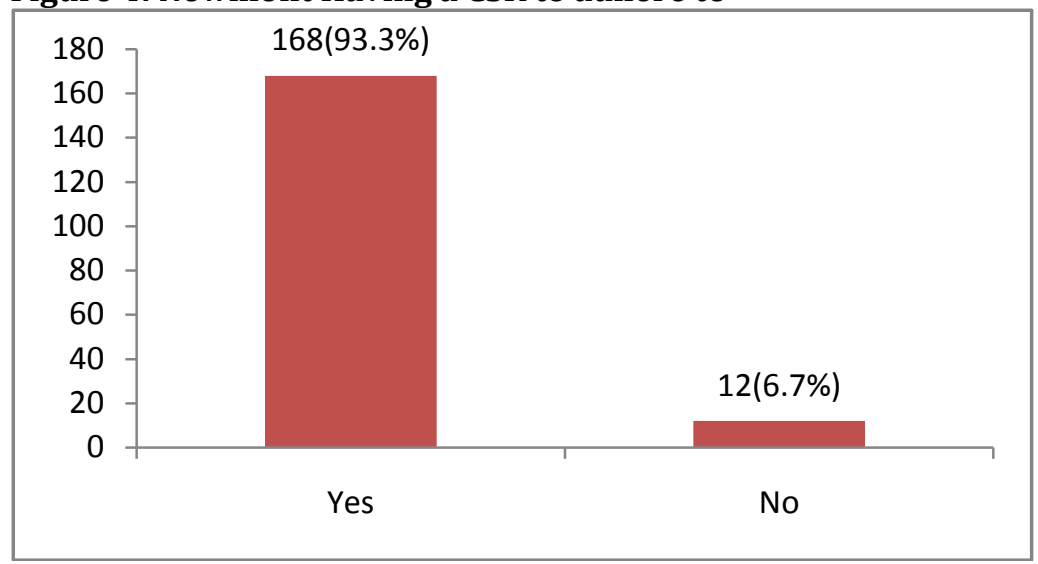

Source: Field Survey, March 2014

It would be necessary to point out that people of the mining Community are not only aware of Newmont having a CSR to fulfil towards them but also, they could point out some specific regulations that bind Newmont to remain faithful to such obligations. That notwithstanding, some respondents still held that it is the traditional customary laws that operated on the land. Apart from that which constituted a negligible opinion, ninety-five of the respondents representing 52.8 percent pointed to other laws with specific reference to the Ahafo Social Responsibility Agreement which was enacted through the Ahafo Social Responsibility Forum. This forum consists of Chiefs of the ten host communities in the mining Community, the Members of Parliament of the two Constituencies in the two mining districts, assemblyman and a youth leader from each town, the chief farmer of each of the two districts of Asutifi North and Tano North, representatives of some other groups, women leaders and some other significant personalities within the region. The greater knowledge of the people of this agreement denotes that the forum is in constant touch with the people and it putting up efforts towards the fulfilment of Newmont's CSR in the region. Eighty respondents representing 44.4 percent on the other hand also made reference to an act of parliament as the binding law of Newmont towards the fulfilment of its CSR in the region as shown on fig. 5.

\section{Figure 5: Awareness of Legal mining codes on CSR}

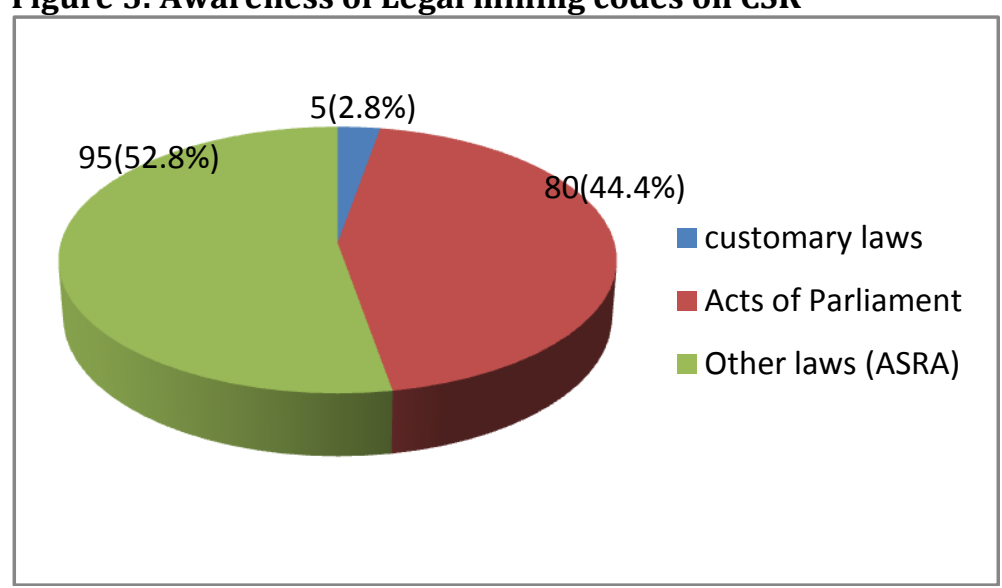

Source: Field Survey, March 2014

To find out the satisfaction of the respondents on the examples of legal codes they have given that binds Newmont to provide socio-economic development to the mining communities, sixty-nine people representing 37.78 percent did not show their view on that. Seventy-one respondents, representing 38.89 percent indicated the people are satisfied with such laws whiles fourteen of them representing 23 percent approximately indicated that they are not satisfied with such laws. The response here indicates such laws, although available, are not the major focus of the people since those who were silent on this view nearly 
equals those who are aware of such binding laws. It is significant to therefore point out that some of the community members would not evaluate the performance of the mining company based on such imperatives but instead, what they see and what they get without necessarily conducting a comparative analysis between the legal codes and Newmont's adherence to them. That notwithstanding, an interview with Honourable Domfeh (2013), an Assemblyman of Wamahinso brought to light that it would be appropriate for Newmont to increase the percentage of contribution towards development of the mining Community from the one percent of their annual profit.

\section{Figure 6 Satisfaction with mining codes}

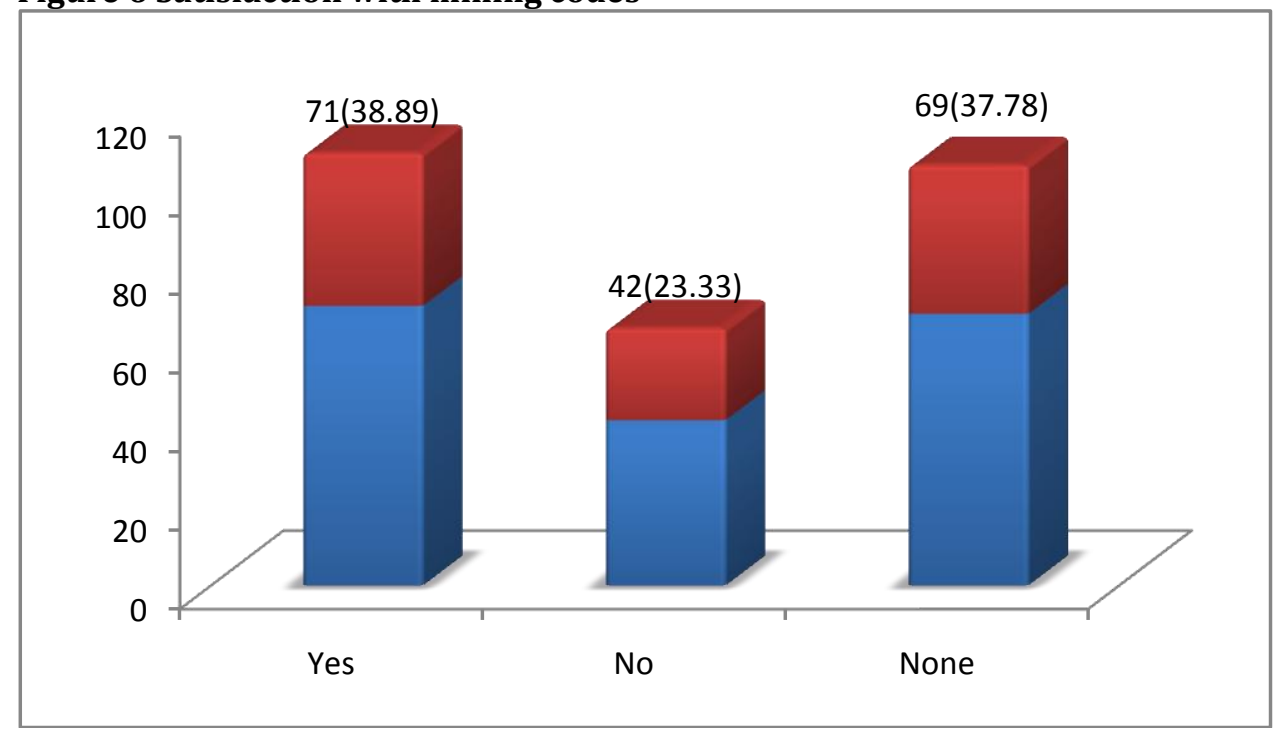

Source: Field Survey, March 2014

Newmont on Health and Environment: There have been questions as to whether the health of people within mining environment is not in danger. The use of heavy duty machines and locomotives emit carbon monoxide into the air always. Prior to mining in the region, inhabitants saw rain water as one of their safest drinking water but have now been advised to stop drinking them due to these emissions. The mine blasts rocks almost every day and this also contribute to such greenhouse gases. The noise that accompanies such blasting is also another issue of concern by the people within the mining environment. Chemicals such as mercury and cyanide are toxic to human life when not well kept. At instances whereby such chemicals spill over their bounds it could affect both human and animal life. For instance, there was a minor overflow of processing solution that occurred at the Newmont Ahafo Mines in 2009 but report from the Environmental Protection Agency (EPA) confirmed that it was contained within the mines and did not get into waters consumed by the residents of the area (Ghanaweb.com, 2009). It has previously been noted also that Newmont has puts up Biodiversity Management Plan in order to protect biodiversity in the mining forest environment in order to protect wildlife from its operations through the installation of wires fences and barriers (Opoku-Ware, 2010). Other measures include the storage of tailings, cyanide and crushed rocks in special facilities with mechanism to detect leakages in order to prevent overflows from reaching rivers nearby (ibid). Land reclamation programmes have also been put up by Newmont to return soil profitable agricultural cultivation after operations. Moreover, it is part of Newmont's operation for organizations such as the Environmental Protection Agency, Ghana Chamber of Mines and the Minerals Commission to exercise oversight over their actives to ensure the necessary checks are always in place in order not to put the lives of the people at the mining communities under danger. Despite such stringent measures, it has however been indicated that natural resources at the mining region had been comparatively altered (ibid). To further substantiate the validity of Newmont's effective measures towards the health of the people and environment as a whole, sixty-three of the respondents representing 35percent objected to the claim that Newmont gives such attention to the people whereas 117 of them, representing 65percent affirmed that Newmont is performing when it comes to the health of the people and environmental issues. This is vividly portrayed on fig. 7. 
Figure 7: Newmont on health

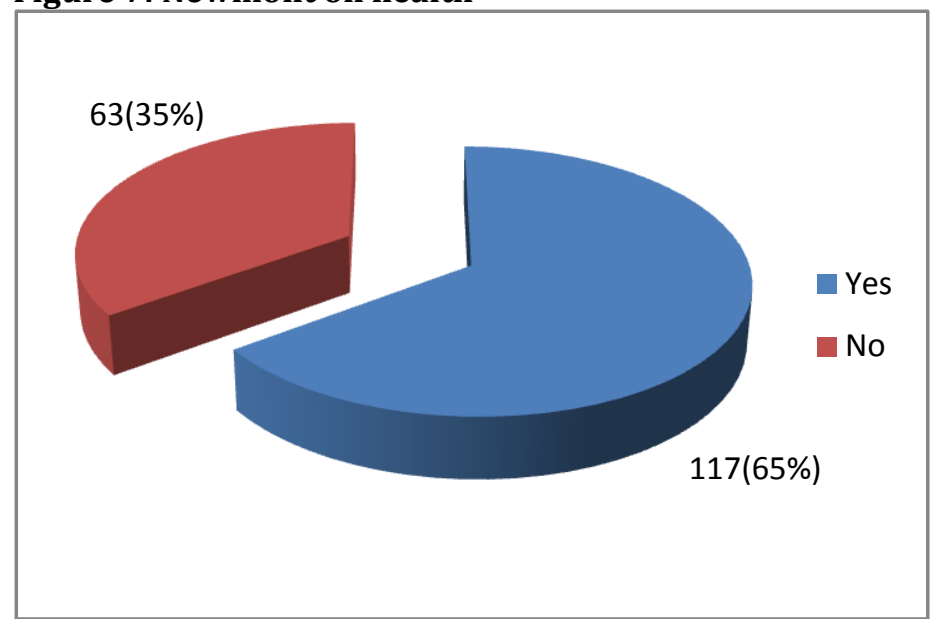

Source: Field Survey, March 2014

Further questioning revealed that although there have been instances where toxic chemicals spill over and attempts to put the lives of residents close to the mine at risk especially those within the villages since they use the water from rivers close by, stringent measures are always put in place to keep such spill under control. That notwithstanding, a respondent disclosed that she is not medically inclined but she still feels some diseases such as skin rashes and challenge with her vision and some residents she knows might have been triggered by the mine operations since she had lived at the area long before Newmont's operations and had never seen or faced such problems until after. This observation is not far from right since previous study by Jones Opoku-Ware (2010) noted that roads at the mining area are not tarred so the mining company conducts regular watering while rain water is no more consumed because of the blasting of rocks. He envisaged that in the next few years major diseases such as respiratory and skin diseases are likely to manifest on a large scale in the community. Through this, it could be possible that such sickness as skin diseases and impairment with vision could be attributed to the activities of the mining company.

On the side of Newmont further with environmental monitoring, the mining company is examining proposals to engage an NGO or University to provide training to local community members to either assist in or to observe formal monitoring of environmental performance and outcomes. According to the social and community development document reviewed, it is envisaged that this would also involve participation of specialist scientific organizations and companies. To add another level of assurance to this, it is planned to set up a small, imminent persons group to validate the methods and independence of the process of monitoring and testing. From the figure above, majority of stakeholders believe NGGL is doing well in their environmental compliance. NGGL, in its EIS report is committed to actively engage community interests into post-closure land use and management planning during the early stage of the mine life. According to NGGL, post-closure land use and management provide potential opportunities related to land productivity and sustainability, resource management, and livelihood enhancement. NGGL intends to collaborate to evaluate these opportunities while ensuring long-term environmental sustainability of post-closure land conditions including impact control measures and environmental monitoring.

What the people gain from Newmont's operations: Kaptstein and Kim (2011) established that Newmont has been a major contributor to Ghana's economy, generating nearly $10 \%$ of the Nation's total exports: $4.5 \%$ of its total foreign direct investment and 1.3\% of Gross Domestic Product (GDP). They further added that Newmont directly produces some 48000 jobs in Ghana and that, it had played a significant developmental role in the communities around the Ahafo mine, and in 2009 alone, it provided 99 local companies with nearly US\$ 6 million in contracts, supporting more than 400 jobs, not including direct and mine employment. As part of its CSR agenda, Newmont Ghana Gold Ltd has sought stakeholder input and feedback regarding a wide range of community development programs and initiatives which among others include the Social Responsibility Forum, the Ahafo Linkages Programme and various Flagship Projects that aim to promote long term economic development planning such as Agricultural Assistant Programme, the Livelihood 
Enhancement Programme and the Vulnerable Programme (Arko, 2013). Barfi and Asare, (2008) pointed out that Newmont's effort to develop local entrepreneurs started in 2007 with the setting up of the Ahafo Linkages Program (ALP) purposely to increase income and employment opportunities for the local communities. These inputs made by the mining company have benefited the local people in diverse ways. On the field of study, twenty nine people representing 16 percent indicated they have benefited on the grounds that Newmont had created jobs for them, seventy-six of them, representing 42 percent of the whole respondents for the research indicated that their benefit is on public facilities such as schools built by the mining company, water, toilets and health facilities, thirty-two of the respondents, amounting to 18 percent of them have benefited through education while thirty one of them representing 17 percent indicated they have benefited from all the various aspects mentioned as seen on fig. 8.

Figure 8: Individuals' benefits from Newmont

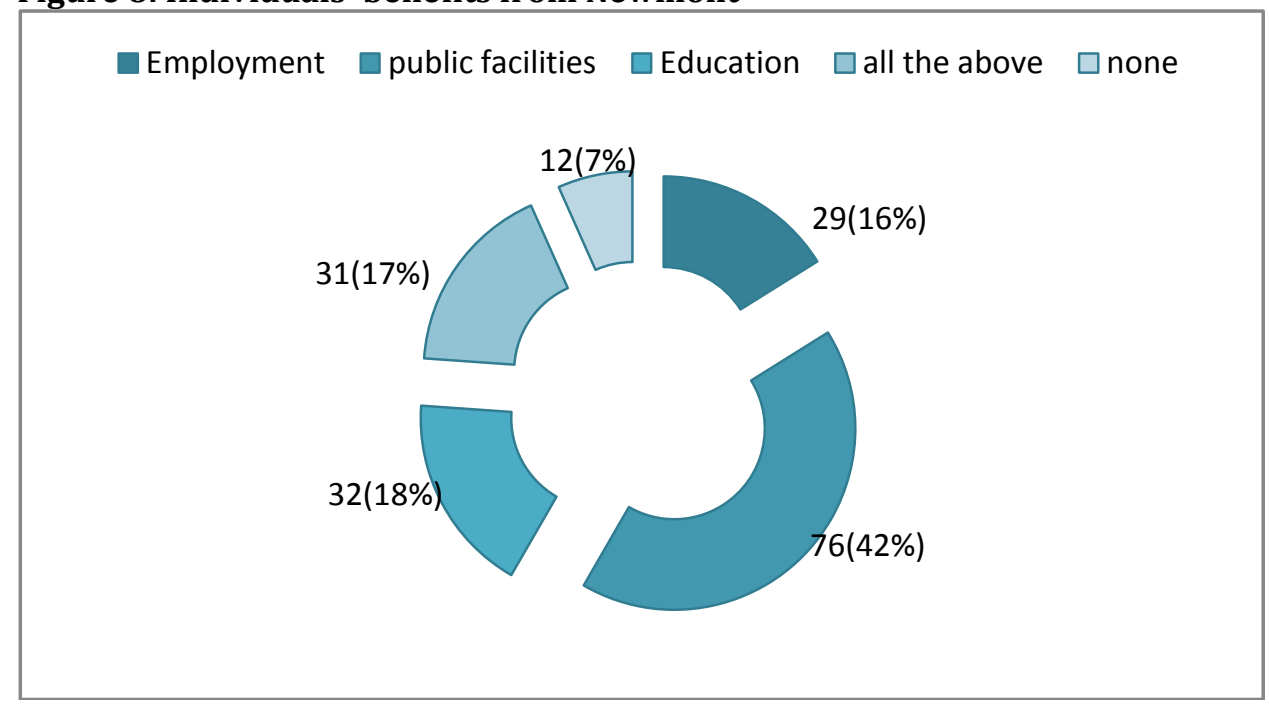

Source: Field Survey, March 2014

Employment: In order for the company to stick to its responsibility of providing jobs to the local people as well as awarding contracts to them, Kapstein and Kim (2011) disclosed that, of NGGL's 1,739 employees, 617 (36\%) have been verified to be local. According to the authors, this is in line with Newmont's commitment to its Social Responsibility Agreement to employ a minimum of 35\% local employees that is people from Ahafo. Also, they observed that, 'of the 2,911 contract employees, 883 (30\%) are local, 1960 (67\%) non-local and 68 (2\%) are expatriates' indicating the involvement of the local people in the operation of the mining company. Ironically, such employment effort has not been able to meet the expectation of the people. It is therefore significant to note that Newmont is not able to employ the greater number of people within the mining communities. One interviewee about the age fifty-five from Ntotroso lamented that he has virtually gained nothing out of Newmont's presence aside the public facilities. This is what he said;

I have gotten nothing apart from the water and the public toilet I benefit from. Some of the people they have taken their lands have finished spending their monies. My worry is that I don't have the skill they need and I am also old. If they take my cocoa farm, my children and great grandchildren will have me to blame. This confirms the observation previously made by Kapstein and Kim (2011) that a higher percentage of NGGL's contracts demand skills which many of the locals do not have. It must also be noted that the Community Relations Review had reported in the year 2007 as a potential challenge to the Ahafo mine that it would not be able to meet the higher demands of local employment (Newmont Community Relationships Review Global Summary Report, 2009). From this, it is clear that not all the people in the mining communities do have jobs despite Newmont's efforts to employ about 30 percent locals to its operations. The respondents therefore pinned employment to only 29 percent. Notwithstanding, Newmont have put up measures to develop the human resource of the area to salvage that challenge of unemployment. 
Social and Human Resource Development: The significant contribution is the public facilities which amount to 42 percent according to the respondents. This is followed by education of which 32 respondents representing 18 percent indicated they have benefited (fig. 8).Newmont Ghana Gold Limited had also contributed in other aspects of education aside from looking at the second cycle and the tertiary education. Primary and Junior High school blocks and teachers quarters had been built in some of the mining towns to ease the pressure that students had been going through previously due to poor accommodation facilities and computer laboratories being provided to some of them to enhance learning. Plates 1 to 6 show some of these contributions in public and educational facilities.
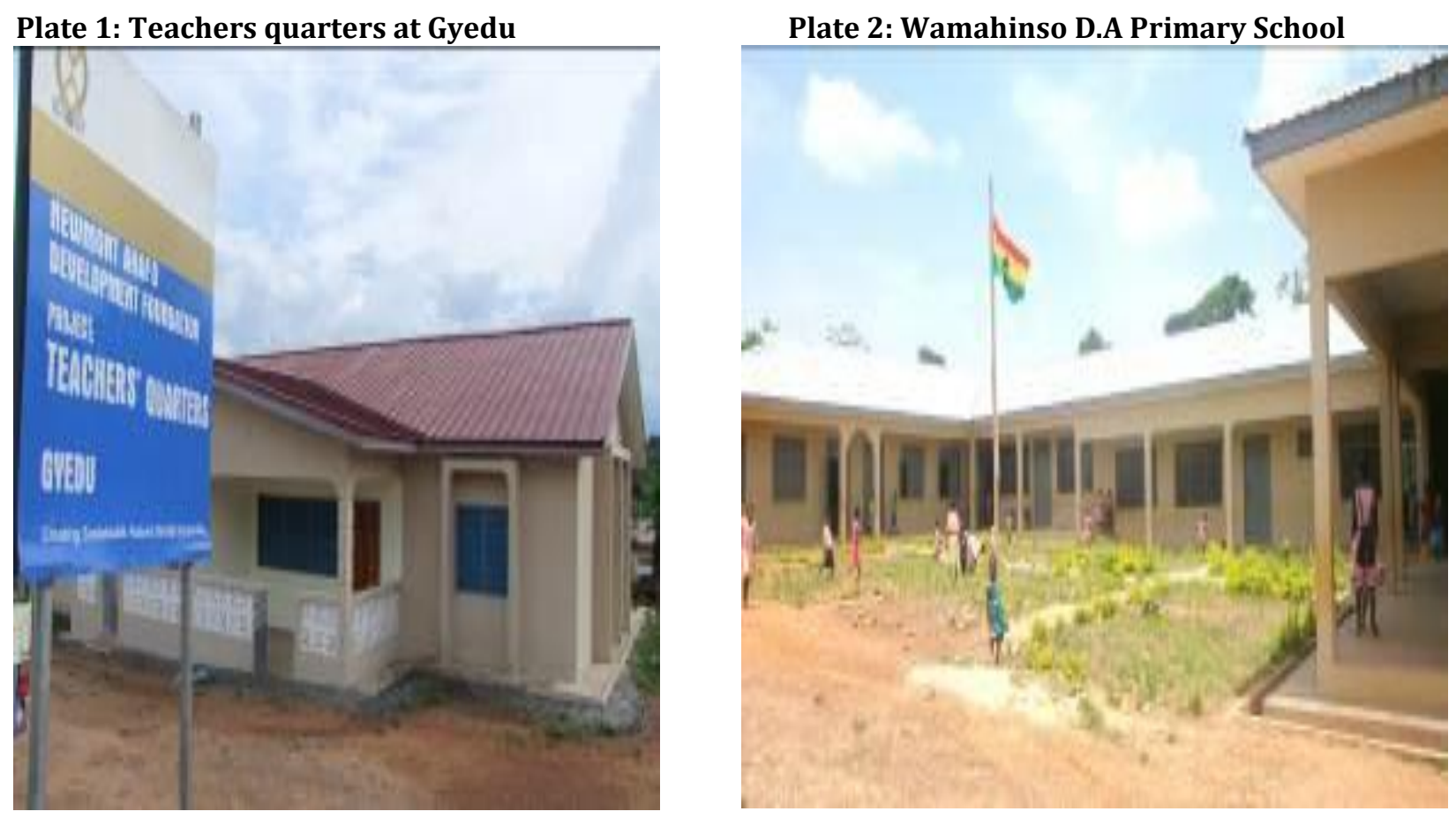

\section{Plate 3: Susuanso Community Library JHS}

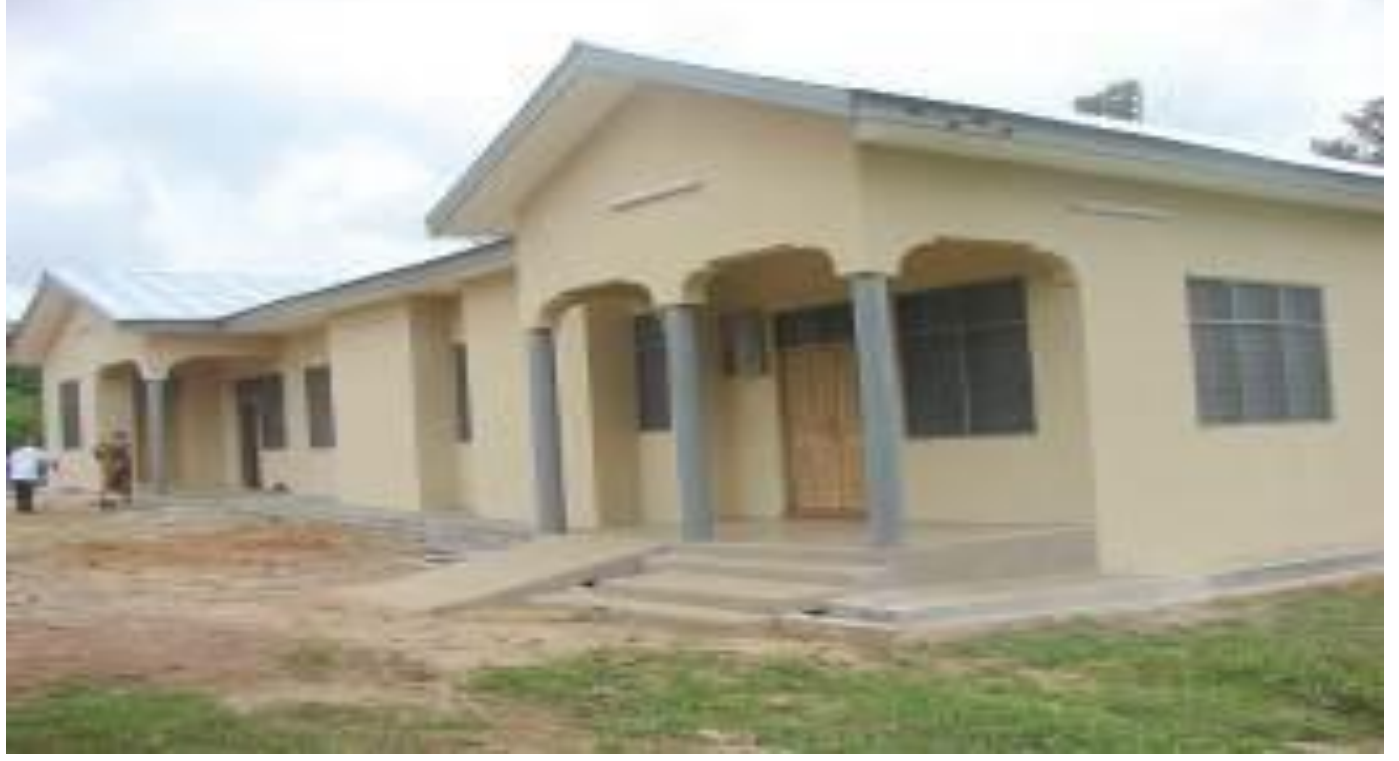


Plate 4: Kindergarten facility for Gyedu Basic School

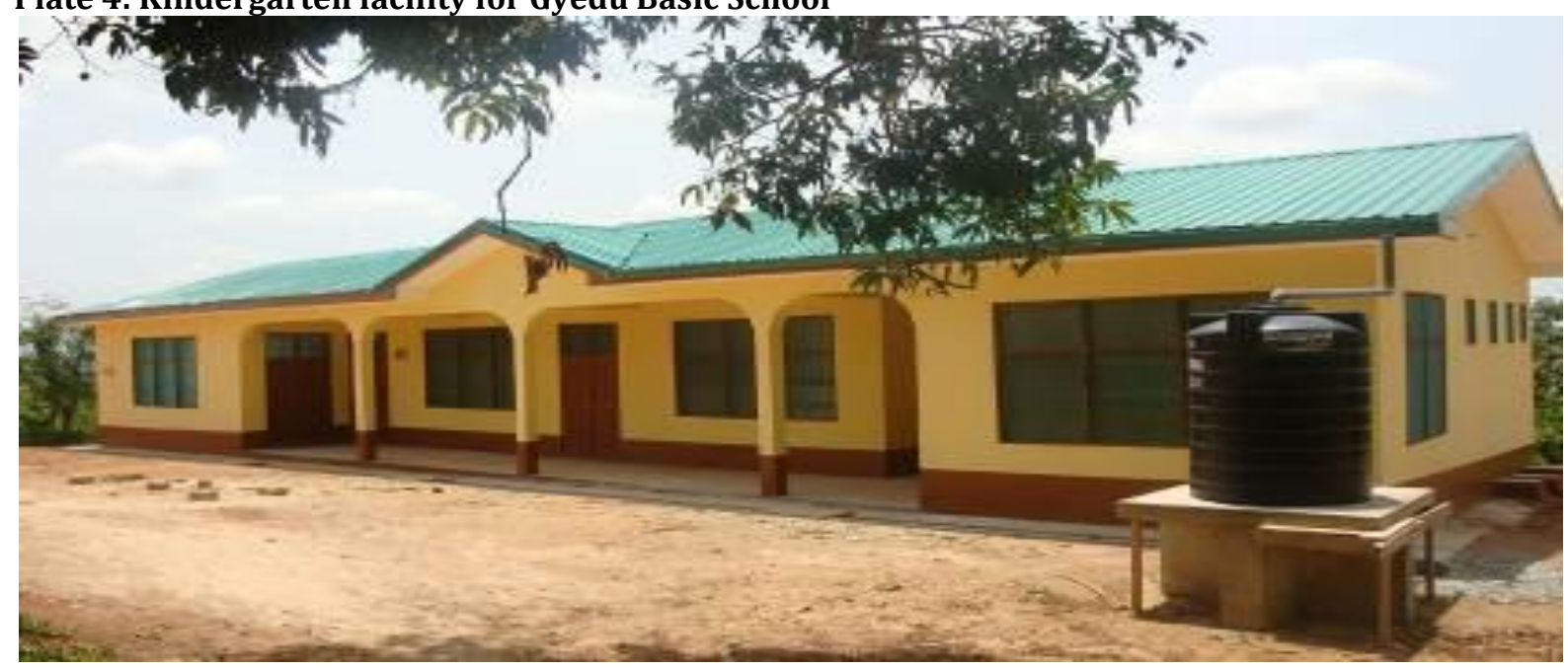

Plate 5: General Ward, Yamfo Health Centre, NADeF report, 2014

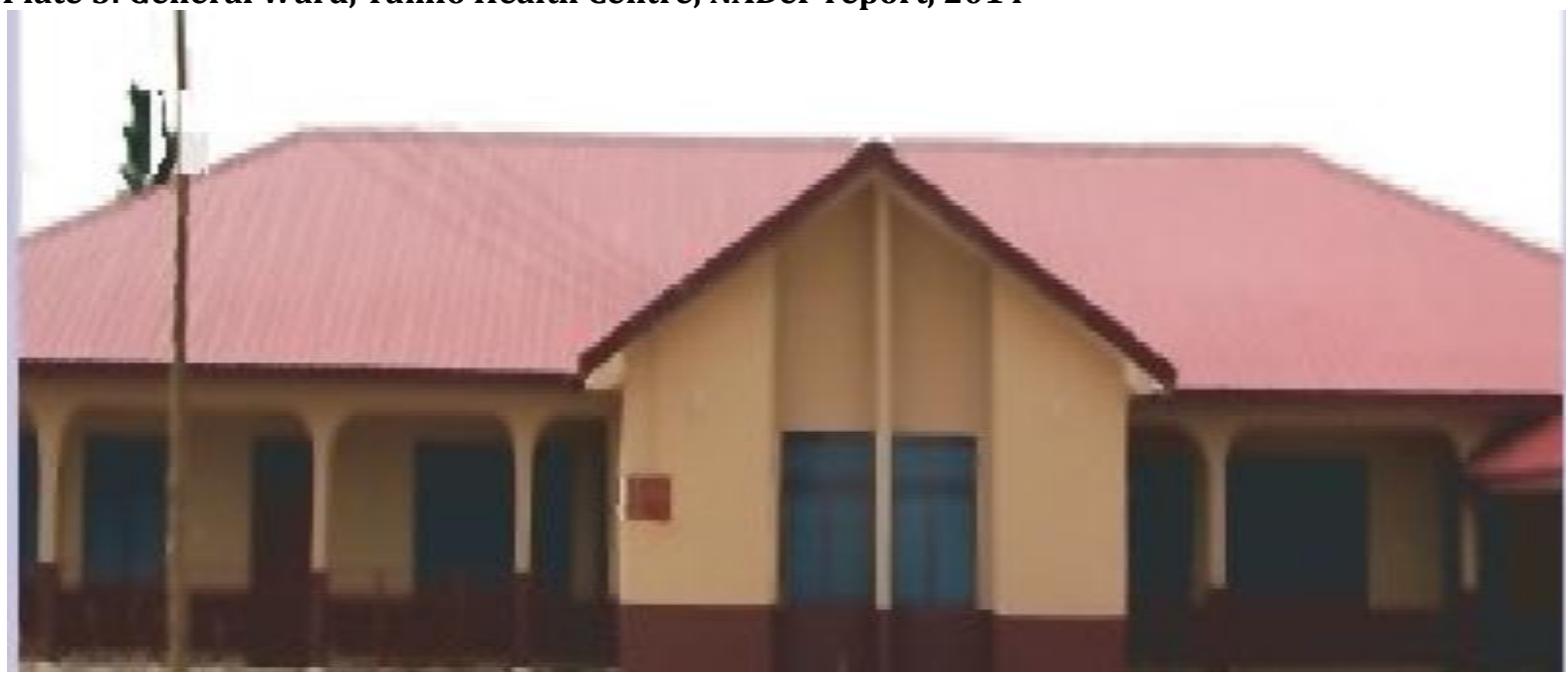

Plate 6: 6-Unit classroom block, Kenyasi No 1 Anglican BS, Ahafo

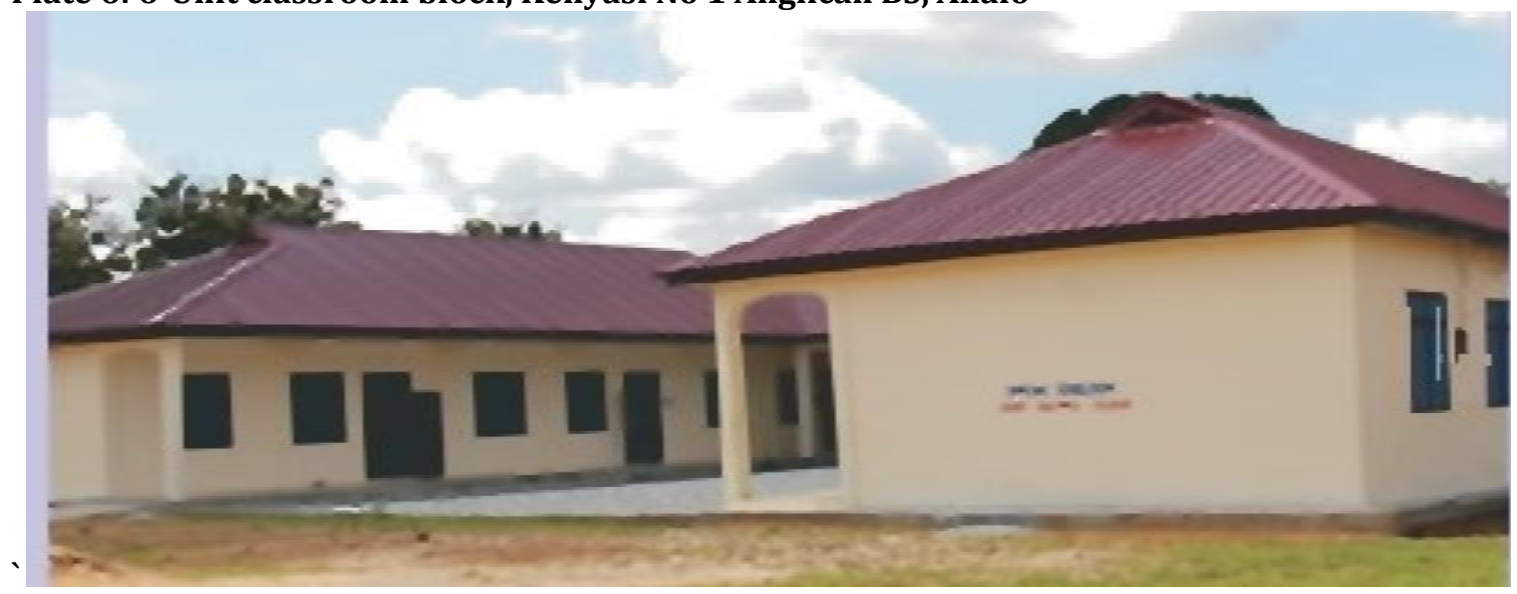

Plate 1-6.NADeF reports 2013 and 2014 
Figure 9: Human Resource Development Statistics

2014 Human Resource Development Statistics

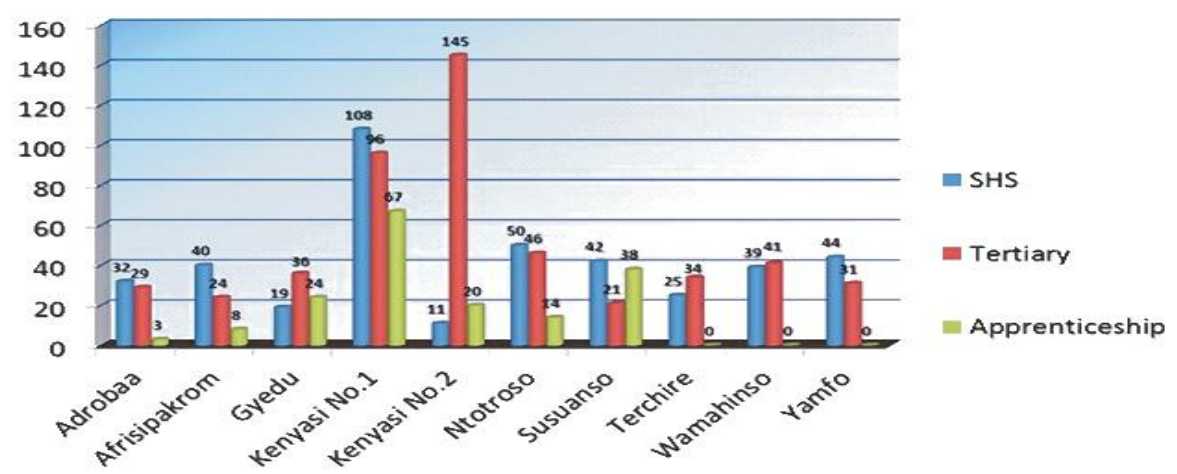

NADeF report, 2014

It is significant to note (fig. 8) that thirty-one respondents representing 17 percent also indicated they do benefit from employment, public facilities and education. Despite the pitfalls, this confirms that such areas the people have benefited are some of the key areas Newmont has been contributing to the development of the mining region. Moreover, fig. 9 indicates Newmont's contribution towards human resource development in the mining area of Ahafo.

Newmont on skill development: On skill development, the Kapstein and Kim (2011) in previous literature had noted that the company has been investing in worker training. In 2009, the company spent US $\$ 3.2$ million on training and on average each worker had 150 hours of skill training. In addition to that, NGGL runs an apprenticeship program, and in 2009, 54 local apprentices were trained in a variety of occupations, with another 50 planned to be trained in coming years. In 2008, Newmont Ghana Gold Limited started to develop local entrepreneurs with the Ahafo Linkages Programme (ALP) purposely to increase income and employment opportunities for the local communities. Another body, Agricultural Improvement and Land Access Program (AILAP), according to the Kapstein and Kim, is a post-resettlement mitigation facility assisting farmers directly affected by the development of the Ahafo Mine. This body will also be further searched into in order to bring out its contributions to the development of Ahafo. On education, fig. 9 shows scholarship support given to deserving students from the region in senior high and tertiary institutions. Kenyasi No. 2 leads with 145 beneficiaries in tertiary education followed by Kenyasi No. 1 with ninety-six beneficiaries, Ntotroso, Wamahinso in that order. Kenyasi No. 1 leads in terms of senior high education with 108 beneficiaries followed Ntotroso with fifty beneficiaries in that order. Also, people are given training in apprenticeship and according to fig. 9, Kenyasi No. 1 leads with sixty-seven apprentices followed by Susuanso with thirty-eight in that order, confirming the continuation of the earlier measures Kapstein and Kim pointed out.

Resettlement and Compensation: Prior to mining companies starting to make profit out of their operations, the lives of people are affected whiles they start with finding a site to install equipment and proceed their operation. In this regard, people's lives become affected hence; they have to resettle some of them sometimes. On this issue of resettlement, majority of the respondents (126 people) consisting of seventy percent had not been resettled before while fifty-four people, corresponding to thirty percent indicated that they have ever been resettled by Newmont before due to its operations. This is an indication that a relatively few of the people have been affected by Newmont's resettlement programs as seen on fig. 10. 


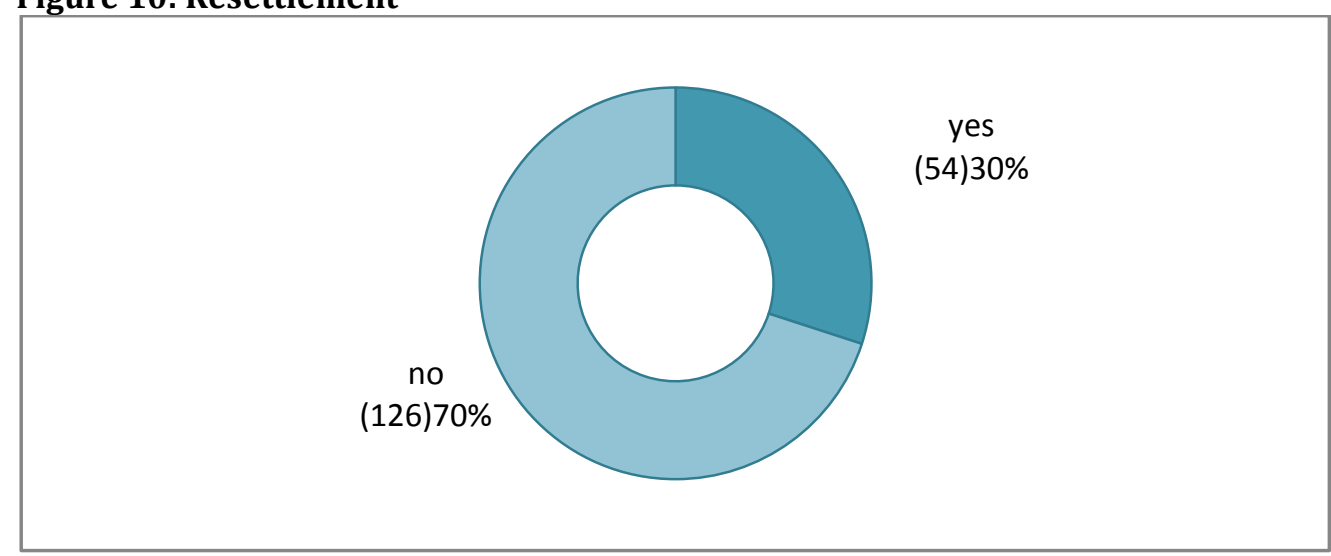

Source: Field Survey, March 2014

According to NGGL and some of the external stakeholders (institutions), compensation has been paid to project-affected people according to parameters and agreed rates set by the elected Resettlement Negotiation \& Compensation Committee and on the basis of non-coerced, prior and informed consent. NGGL stated that people were offered choices between acceptable, fair and equitable alternatives. Compensation included full replacement cost of structures, assistance with moving personal belongings, efforts to improve former living standards and compensation for crops. Land, housing, infrastructure and other compensation were provided to the adversely affected population. Even though some of the institutional stakeholders think that NGGL is doing very well, others especially residents of host communities perceive that the company is performing poorly with regard to compensation packages.

Figure 11: Assessment of Compensation

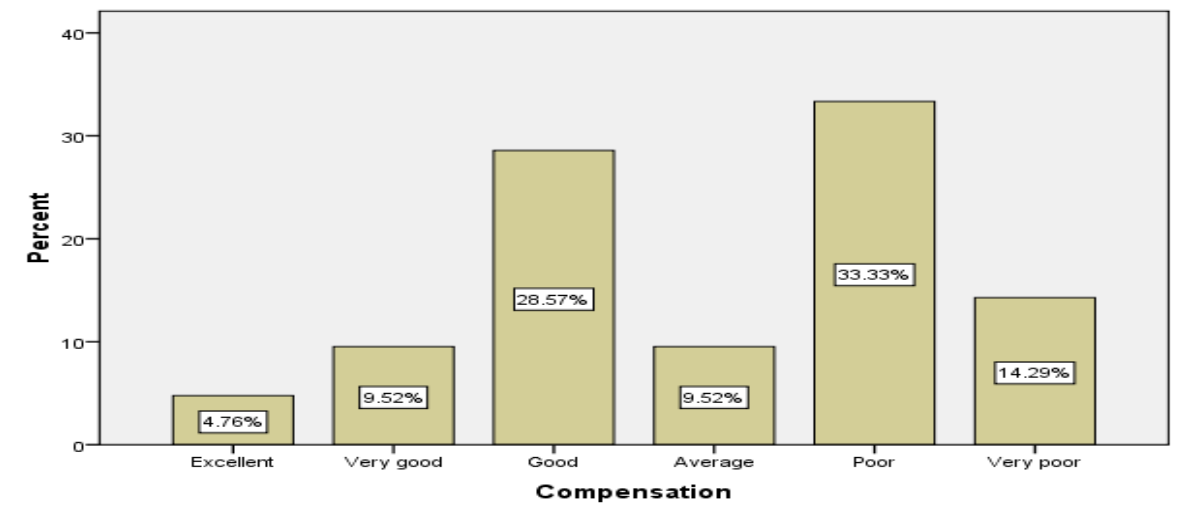

Source: Field Survey, March 2014

On the contrary, some community members that have been resettled have argued that the crops grown by the farmers of the region which could have catered for the present and future generations such as cocoa and teak were underestimated by the company resulting inadequate compensation packages being given to the people affected. Moreover, compensation, according to some affected people, made no room for the land upon which the crops are cultivated. However, the land is a fixed asset which would benefit future generations in diverse way aside from cultivating crops. The harder part of the issue is the unattractive compensation of such lands that were not under cultivation. Although it may be argued that Chiefs are in charge of such lands, it does not deny the owners of such lands their entitlements. Again, the land tenure system of the region does not feature continuous cropping. There are times the land must be given rest to fallow for some years depending of the kind of farming the owner intends to practice on the land at the end. For instance, a farmer cultivating maize on a land for about five years would need to leave the land to fallow for some period of time before cocoa could be cultivated. Another observation was that the mode of payment of the compensation package did not satisfy most of the farmers by paying the premium once without any benefits in the subsequent years. This is 
not really helping the households to sustain their means of livelihood for the rest of their lives. Most of the farmers are ignorant of the best and available opportunities to invest these compensation monies and this result in "unwise" ways of spending. They prefer monthly or yearly payments to avoid the hardship they go through after spending everything within the first year. All these add up to indicate that the compensation packages were not up to satisfaction. This confirms previous findings of Kapstein and Kim who noted that, 1700 households were resettled, with compensation including cash amounting to US\$45 million and however lamented that the biggest problem of Newmont Ghana Gold Limited at Ahafo is the fact that many households that were not affected by the mine came seeking compensation and new housing. This therefore seeks a second look at the whole resettlement programmes, crop rating probably a better means of compensating affected people either annually or monthly instead of the payment at a goal. In a Focus Group Discussion a saleswoman at the Ntotroso resettlement site indicated that;

We miss the livelihood we have lost back at the village. Over there you are close to your farm, you don't need a car to go and fetch food, and you don't need to buy vegetables all year round because you cultivate it alone. But now you have bought almost everything if all of your land was taken by the mining company (Field Survey, March 2014).

Newmont on Cultural heritage and recreation at Ahafo: Newmont is committed to respecting the Culture of the people within the mining communities. In this regard, to be concerned with whether the effect Newmont's presence is having at the culture of the people of the mining companies is positive or negative; forty respondents representing 22.3 percent hold the view that the presence of Newmont has had no effect on their culture. Eighty of them, representing44.4percent think the impact is positive on their culture while sixty of them representing 33.3 percent believe the impact on culture has been negative as shown on fig. 14 .

\section{Figure 12: Impact of Newmont's presence on Culture}

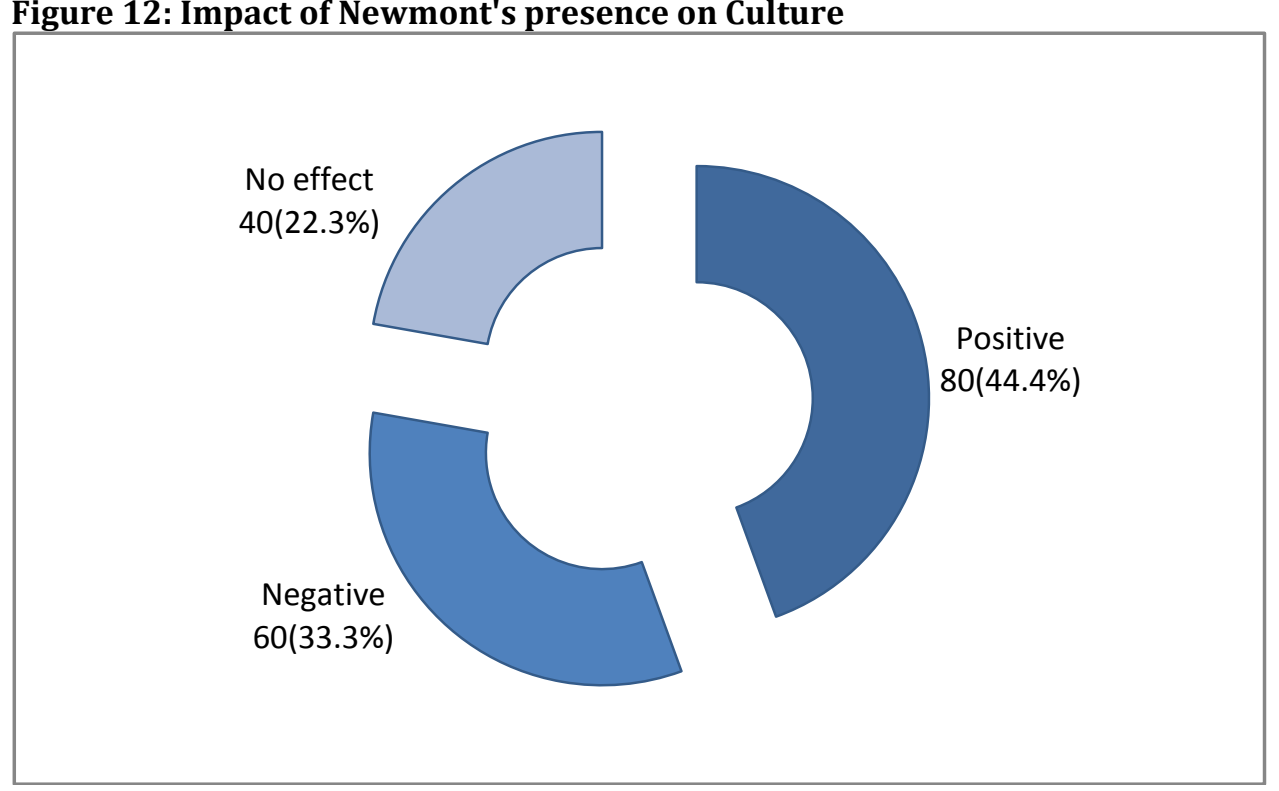

Source: Field Survey, March 2014

Newmont had also not neglected the culture of the people as it has made it a responsibility, as spelt out in the Social Responsibility Agreement, to respect the culture of the people. It was said by Honorable, the Assemblyman of Wamahinso that the mining company indeed respects the culture of the people and do contribute to its preservation by donating to support the Apumasi festival of Ntotroso, building of Palaces and other projects for that regard (Field Survey, 2014). This is confirmed by the report of NADeF for the year 2010 whereby NADeF supported the Apumasu festival with an amount of GH\$15,000.00 (US\$10,563.38) (NADeF report, 2013). This event was coupled with sporting activities to carry the youth along as there was an organized football competition for schools in Ntotroso and its satellite communities as well as their town 
teams. Communities that featured the Apumasu sports fiesta included Wamahinso, Ntotroso and Gyedu. NADeF supported this event with funds amounting to GH $\$ 8,000.00$ (US\$5,633.80) (NADeF report, 2013).

\section{Plate 10: Teams posed for action during the sports fiesta, Apumasu Festival 2010}

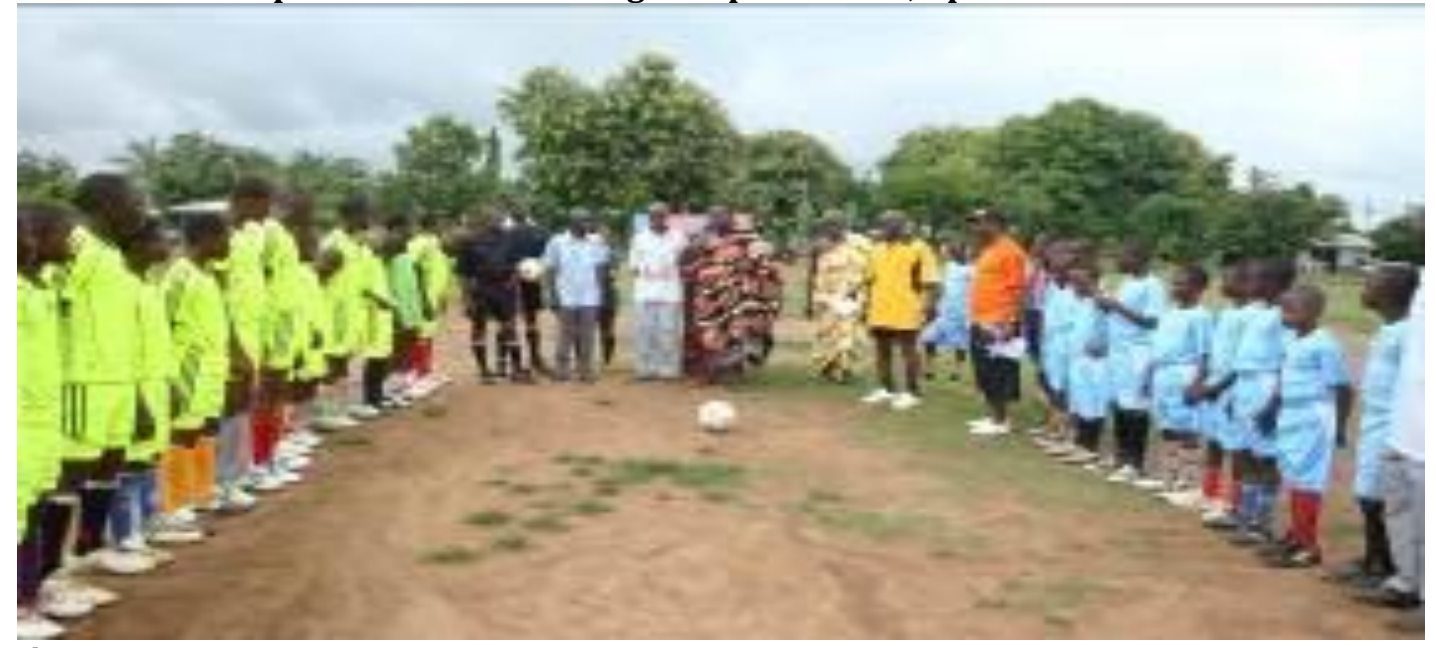

Plate 10, NADeF report, 2013.

Newmont on Peace and Stability: For Newmont to have peace of mind and continue to mine at Ahafo, there must be peaceful co-existence between the mining company and the people of the mining communities. In view of that, there was the need for how the people air their unhappiness towards the mining company if they are not happy with something it does. A maximum of 139 respondents, representing seventy-seven percent approximately indicated that such dissatisfaction is expressed through demonstrations. It has previously been observed in the Community Relationships Review (2000) on Newmont's operation at Ahafo that in 2006 some people near the mine revolted because Newmont do not provide them with jobs and such resistance led to the death of one person. During an interview with one Youth Leader in the mining communities, it was found out that although Newmont is employing the youth, it would be much expedient for more of the youth to gain employment because more are still unemployed. Nine people representing 4.8 percent said the people file lawsuits against Newmont as such instances while Thirty-two people, representing 18 percent approximately said the people do that by summoning Newmont before the traditional council for redress as shown on fig. 15.

Figure 13: How communities' members show dissatisfaction

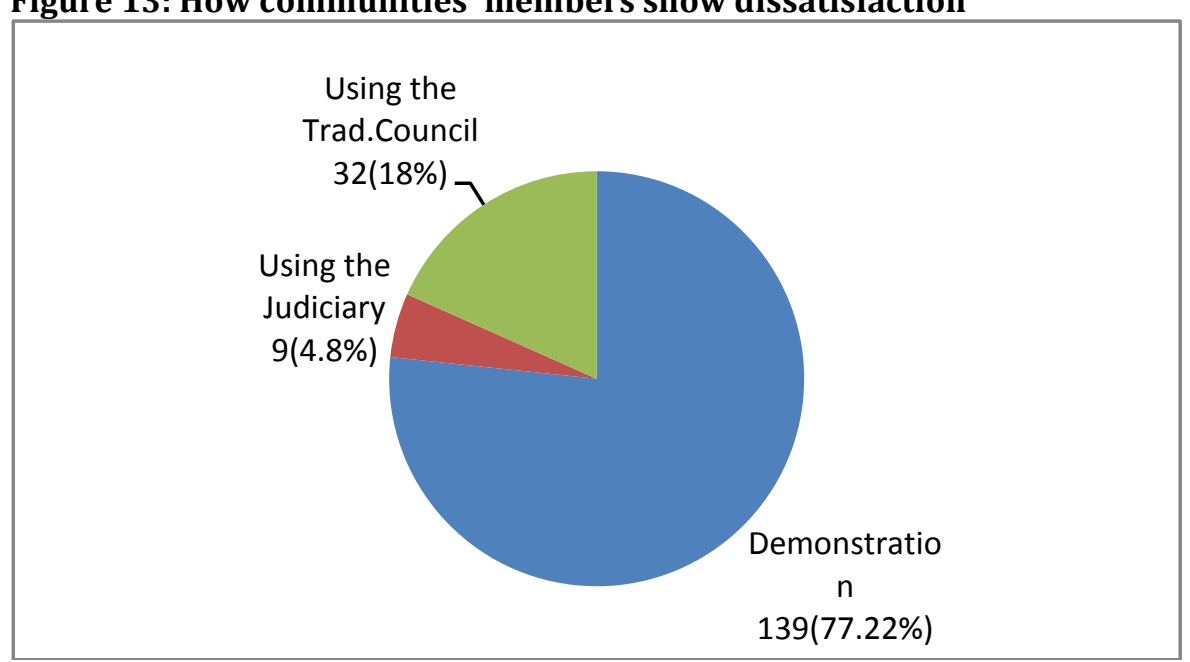

Source: Field Survey, March 2014 
As a means of handling disagreements between Newmont and the people of Ahafo, the Ahafo Social Responsibility Agreement, among other things put up a measure of dealing with conflict with a clause that Newmont and the Community (the mining communities) agree to exercise patience and tolerance and resolve issues through dialogue and negotiations for the purpose of maintaining good working relations (Ahafo Social Responsibility Agreement, 2008). In order to further probe into the relationship that exists between Newmont and the members of the mining Community, the people indicated whether the relationship is not good at all, satisfactory or very good. Thirty-seven of the respondents representing 21 percent indicated that the relationship is very bad; ninety-seven of them representing 54 percent said it is satisfactory while 46 of them corresponding to 25 percent said the relationship is very good as shown on fig. 14 .

Figure 14: Relationship between Newmont and people

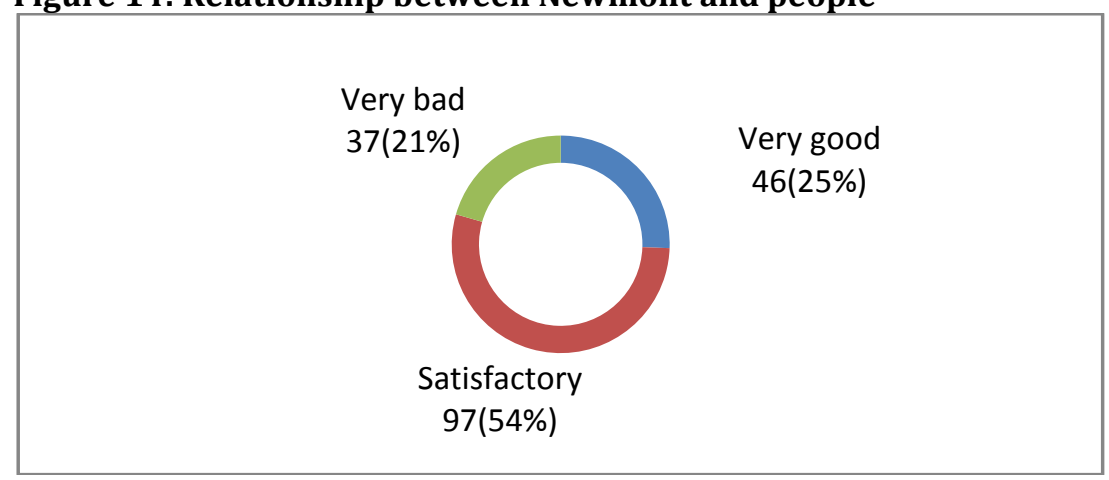

Source: Field Survey, March 2014

This indicates that largely the Newmont's relationship with the people is cordial. This is very essential as the Ahafo Social Responsibility Agreement mentions effective communication between Newmont and the mining communities at Ahafo. That notwithstanding, few people still have reservation about such relationship as they indicating that it is bad. Since they are part of the people at the grass root, it calls for Newmont and the ASRF to ensure effective grass-root participation in matters concerning the people including compensations, resettlement, employment and job training.

Shortfalls of Newmont's operations at Ahafo: The presence of Newmont at Ahafo has not only brought positive impacts on the lives of the people of the region. Some of the challenges that the mining had brought on the people range from economic, health and socio-cultural. In finding out which facet of human endeavour such negative impact emanate from, forty-five of them, representing 25 percent said the negative impact of Newmont's activities on the mining communities has been on their economic lives, eighteen of them, representing 10 percent indicated it is a social problem, fifteen respondents which corresponding to 5.6 percent pointed out that it is a cultural problem and seventy-six of them, representing 42 percent noted the impact has been on the health of the people of the mining communities as shown on fig. 12.

Fig. 15: Newmont's negative impacts on individuals

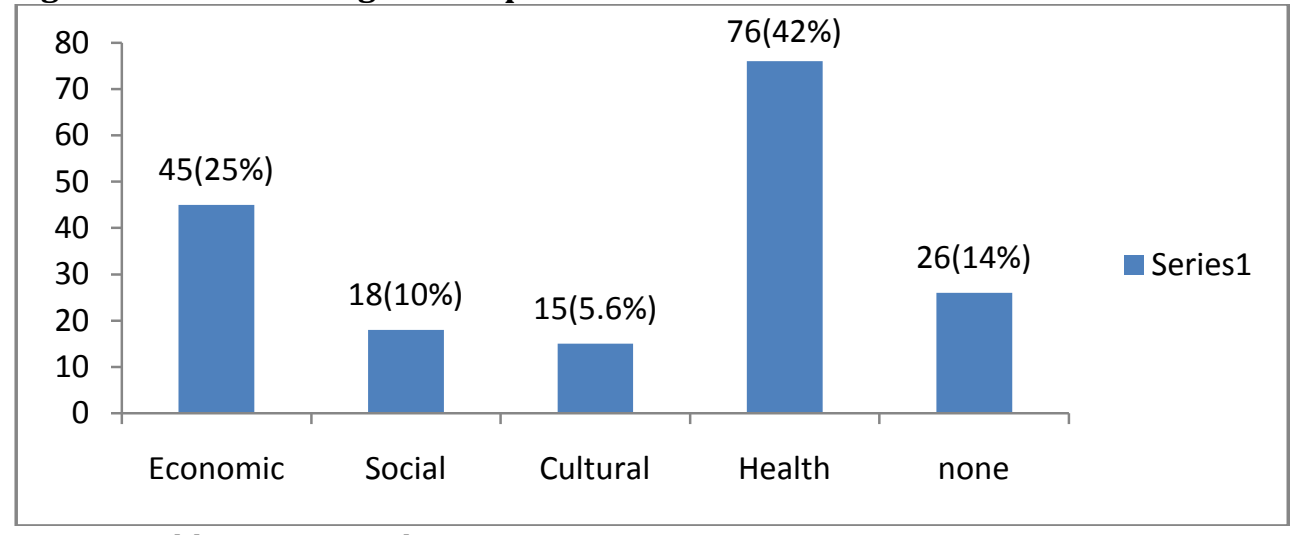

Source: Field Survey, March 2014 
Specifically, some of the respondents explained that cost of living in the mining region had increased considerably. They pointed out that prior to the mining in the region, prices of goods were relatively cheaper. However, the mining has seen an influx of people from all walks of lives to seek greener pastures in the region and this had contributed to consistent increase in prices of local goods such as charcoal, oil palm, vegetables, bush meet. Non local goods such as clothing and hardware have seen their prices vehemently increased. One respondent said in a Focus Group Discussion said that 'all people know is that there is gold here so we have money and so they sell goods at higher prices. The problem here is that those who have jobs can afford them without pain but some of us without jobs and no skills to work with the mining company are at the losing end'( Field Survey, 2014).

This is an indication that the gap between the rich and the poor is gradually widening. On the cultural front, an old woman said that 'our values are gradually wearing away because some of our taboos are broken such as sacred days and sacred grooves are no more the concern of many'(Field Survey, 2014). This comes partly as a result of the fact that the mining company do operate without such observances as sacred days and so some people use it as a stepping stone to flout such taboos. On the other hand, people from different cultural backgrounds have settled in the region due to such mining activities and sometimes this leads to blending of cultural practices and this sometimes lowers the distinctiveness of the culture of the people in the region. On health wise, some indicated that the rise in cost of living had of late had a negative repercussion on their ability to seek medical attention. Despite the efforts put in place by the mining company to employ the local people, the challenge had been the lack of skills on the part of the locals. This leads to many grownups facing especially those above fifties finding it difficult to make earns meet due to the comparative increase in cost of living. An interviewee about age fifty-five complained that he has '...no job to do and has no skills required by the company (Field Survey, 2014).

Another identified negative impact during the study was adverse repercussion of some programmes adopted by the mining company. The redundancy exercise embarked by Newmont in 2014 according to Ghanaweb.com (ghanaweb.com, 2014) consisted of 400 people from the Ahafo operations area. On the field, the Assemblyman of Wamahinso lamented that the exercise had rendered some locals jobless apart from those who are still waiting for jobs. Moreover he pointed out that the Community Liaison Officer of Wamahinso had been affected by the exercise. It is important to note that the role of the Liaison Officer is to mediate between the mining company and the communities. His layoff here therefore points to a break in that important role he had played earlier. It would therefore be necessary if certain positions are made entrenched by the company to preserve significant positions for effective communication purposes. This is essential because communication had previously been recommended by Ababio and Boon (2009) for the need for effective communication at the local levels. Also, Hon. Further indicated that it would be very necessary for the one dollar per ounce contribution by Newmont to be increased'. Various concerns have been raised on what mining companies contribute towards socio-economic development. For instance, Stephen Yeboah (2011) of the Centre for Social Impact Studies (CeSIS) advocated for the review of confidentiality clauses by government that 'give undue advantage to mining firms' by noting that Newmont and other multinationals despite Parliament's review of increase of royalty payment to 5 percent still pay 3 percent. This still calls for improvement of the contribution of Newmont towards development in the mining communities.

\section{Conclusion}

Since Newmont Ghana Gold Limited started operation at Ahafo, it had immensely contributed to the socioeconomic development of the mining communities of Ahafo and therefore doing well with its CSR despite the shortfalls. Since 2003, effort was made to provide the people immediately affected by the mining company's operation such as compensation for loss of farms and other resources. By 2005, people were being resettled by the mining company with houses being put up for them as well as compensation in the form of cash. The pouring of gold by the turn of 2006 helped Newmont to strengthen its Corporate Social Responsibility agenda at Ahafo. As a CSR gesture, mutual agreement between the mining communities and Newmont saw the establishment of Newmont Ahafo Development Foundation, an idea that was conceived and birthed by the Ahafo Social Responsibility Agreement. Newmont Ghana Gold Limited had not only created jobs for the people of the region but also, worked on human resource development by providing scholarships to qualified 
and deserving students at second cycle institutions and the tertiary level. It is has also been organizing vocational training for people of the region whereby some are being employed and the others create their own jobs. Culture and sports had not been left out as Newmont had been providing funds for the organization of such events through NADeF as well as the building of chief palaces. It has also been discovered that prior to making profit, Newmont's contribution largely focused on the immediate environment of its operation but upon firmly establishing itself it had the opportunity to broaden its tentacles and positively impact the lives of the people through human resources development, health, culture and sports. Some affected persons under Newmont's resettlement programme are not satisfied with their compensations since they have virtually spent what they were given and have no work to do. Also, poverty is another challenge on the part of those who are unable to get jobs as a result of the sharp increase in cost of living in the region.

The discussions on the mining companies which operate in Africa have severally been negative. Newmont company which operates in different continents including Africa has been listed to be performing creditably in the area of corporate social responsibility in Ghana. In particular NGGL directly and indirectly has supported some 48,000 jobs in Ghana and NGGL played a significant developmental role in the communities around the Ahafo Mine and in 2009 alone provided 99 regional companies with nearly US\$6 million in contracts, supporting more than 400 jobs, not including direct employment. Although several Authors and reports including the works of Kitula (2006), Hamann (2003), Hilson (2002), Traore (1994) among others continue to project the negative impact of mining activities especially those owned by expatriates. The Newmont example has the tendency to influence the intellectual discourse in favour of mining companies on the continent of Africa, especially South Africa which has had bad press on the nature of the relationship between mining labour (employees) and employers. The Ahafo Ano example potentially can throw some light on the broader discourse on expatriate mining in Africa. It is significant to point out that Newmont's Ahafo Mine has not yet experienced much of the worse repercussions of mining not only due to effective mechanisms but also, the relatively short time period of operation. It would therefore be necessary for Newmont to persistently put up stringent measures as part of deepening its Corporate Social Responsibility in order to prevent present and future generations of the region from tasting the woes of mining.

\section{References}

Adu-Gyamfi S., Owusu-Ansah, D., Brenya, E. \& Damtar, D. (2016). Artisanal Mining and Its Ramifications on the People of Prestea. Current Research Journal of Social Sciences, (forthcoming).

Akabzaa, T. (2004). African mining codes; A race to the bottom. African Agenda, 7(3), Print.

Amponsah-Tawiah, K. \& Dartey-Baah, K. (2012). Corporate Social Responsibility in Ghana. International Journal of Business and Social Sciences, 2(17).

Arko, B. (2013). Corporate social responsibility in the large scale gold mining industry in Ghana. The Business and Management Review, 4(1).

Asante-Manteaw, A. (2011). An appraisal of the land access processes in the mining industry in Ghana: The case of Newmont Ghana Gold Limited (NGGL) Ahafo mine. Unpublished master thesis of Commonwealth Executive.

Attitudes of Mining Communities. (2012). A Challenge to Newmont. Tuesday, 28th August, 2012

Atuguba, R. \& Dowuona-Hammond, C. (2006). Corporate Social Responsibility in Ghana Friedrech Ebert Foundation-Ghana.

Barfi, I. \& Akrasi, G. (2008). 40 Million Euros Granted for Ministry of Lands, Forest \&Mines. The Independence, April 10th, 2008.

Boon, E. K. \& Ababio, F. (2009). Corporate Social Responsibility in Ghana: Lessons from the mining sector. International Association for Impact Assessment Conference Proceedings, 2009.

D'Amato, A., Sybil, H. \& Sue, F. (2009). Corporate Social Responsibility and sustainable business; A guide to Leadership tasks and functions. Centre for Creative Leadership, Greensboro, North Carolina.

Domfeh, K. (2013). A Miner's CSR Guideline to Reduce Social Conflict.

Extracting Africa's Minerals. (2003). At What Cost. 'African Agenda Vol 16 No. 2, 2003.

Ghanaweb.com. (2009). EPA: Chemical Overflow at Newmont Did Not Reach Public. General News Ghana web.Web.2009.http://www.ghanaweb.com. Accessed on 24th October, 2013.

Hamann, R. (2003). Mining companies' role in sustainable development: the'why'and'how'of corporate social responsibility from a business perspective. Development Southern Africa, 20(2), 237-254. 
Hilson, G. (2002). An overview of land use conflicts in mining communities. Land use policy, 19(1), 65-73.

Jenkins, H. \& Obara, L. (2008). Corporate Social Responsibility in the mining industry- the risk of community dependence.

Kitula, A. G. N. (2006). The environmental and socio-economic impacts of mining on local livelihoods in Tanzania: A case study of Geita District. Journal of cleaner production, 14(3), 405-414.

Kapstein, E. \& Kim, R. (2011). The Socio-Economic Impact of Newmont Ghana Gold Limited. Stratcomm Africa. Mireku Gyimah Daniel Mining and Social Responsibility: An Exemplary Model for Quality Life.

Nemont.com. (2015). www.newmont.com/home/default.aspx

Newmont Ahfo Development Foundeation.2013 Report.

Newmont Ahfo Development Foundeation.2014 Report.

Newmont Ahfo Development Foundation. (2008). Ahafo social responsibility agreement.

Newmont Global Summary Report 2009, Community Relationships Review.

Nwete, B. (2007). Corporate Social Responsibility and Transparency in the Development of Energy and Mining Projects in Emerging Markets; Is Soft Law the Answer? German Law Journal.Vol.8 No. 04.

Opoku, M. S., Amoako-Arhen, A. \& Okyere, A. A. (2014). Goldfields Ghana Limited, Tarkwa Mines and Community Infrastructure Development in the Tarkwa Nasuaem Municipality of Ghana. Journal of Studies in Social Sciences, 6(2).

Opoku-Ware, J. (2010). The Social and environmental impact of mining activities on indigenous communities; The case of Newmont Gold (Gh) Limited (Kenyasi) in Ghana. Unpublished MA Thesis in Development Management, University of Agdaer.

Traore, P. A. (1994). Constraints on small-scale mining in Africa. In Natural Resources Forum, 18(3), 207-212). Blackwell Publishing Ltd.

Yankson, P. W. K. (2010). Gold Mining and Corporate Social Responsibility in the Wassa West District, Ghana. Development in Practice, 20(3).

Yeboah, S. (2011). Has Mining Served Ghana Well? http://www.modernghana.com. Accessed on 24th October, 2013.

Graphic Online. (2015). The Impact of Mining in Ghana. Assessed from http://graphic.com.gh/features/opinion/45022-the-impact-of-mining-inghana.html\#sthash.yPUZJcKa.dpuf on October, 16, 2015.

Ghanaweb.com. (2014). Mineworkers kick against Newmont redundancy stance. Assessed from http://mobile.ghanaweb.com/GhanaHomePage/NewsArchive/Mineworkers-kick-against-Newmontredundancy-stance-311427 on September 1, 2015. 